\title{
Outcomes of Corrective Surgery in Children with Foot Deformities Using Quantitative Gait Analysis
}

\author{
Joana Francesca B. Visperas, MD*, Carlo Emmanuel J. Sumpaico, MD* and Ilian Dominiq D. Eusebio, MD \\ Department of Orthopedics, Philippine General Hospital, University of the Philippines Manila
}

\begin{abstract}
Objective. This study aimed to quantitatively define outcomes of corrective surgery in children with various foot deformities.

Methods. We used a retrospective, nonrandomized design. All pediatric patients who underwent pre and postoperative gait analysis and corrective surgery were included. Outcome measures included quantitative gait analysis with temporospatial and kinematic parameters, the Gait Deviation Index, Gillette FAQ, and Hoffer's criteria.

Results. Five patients with neurogenic and idiopathic deformities underwent corrective surgery at the Philippine General Hospital from 2015 to 2017. Comparison of gait pre and postoperatively show promising outcomes, with improvement in GDI and FAQ levels, despite some of the patients' need for braces.

Conclusions. Quantitative gait analysis is a suitable method for evaluating surgical outcomes for foot deformity correction. It can be used in combination with functional outcome measures and clinical examination to give an overall picture of a patient's walking ability.
\end{abstract}

Key Words: gait analysis, foot deformity, clubfoot, gait deviation index

\section{INTRODUCTION}

Foot deformities in walking children are often seen with cerebral palsy, spinal cord abnormalities, peripheral neuropathies, and residual deformities in idiopathic talipes equinovarus. These deformities cause gait abnormalities, which are often associated with an increased need for walking aids and the development of callosities at the abnormal pressure points. Callosities make brace and orthotic wear more challenging, especially for patients with sensory abnormalities. If these deformities persist into adulthood, increased body mass would increase the magnitude of abnormal loading and would, in turn, increase the possibility of early degenerative arthritis. ${ }^{1}$

The treatment goal is to provide a stable base for an effective lever arm in the gait stance phase. ${ }^{1}$ Mild deformity may benefit from a combination of physical therapy, serial casting, and bracing. ${ }^{2}$ Surgical correction is often necessary for more advanced cases or those unresponsive to conservative

${ }^{*}$ Dr. Visperas and Dr. Sumpaico shared first authorship for this paper.

Corresponding author: Joana Francesca B. Visperas, MD Department of Orthopedics Philippine General Hospital University of the Philippines Manila

Taft Avenue, Ermita, Manila 1000, Philippines

Email: cheskavisperas@gmail.com management. The foot's balance can be addressed by tendon transfers, while osteotomies may be used for rigid deformities. Arthrodesis is almost always the last option of treatment. ${ }^{1}$

Tendon transfers have been done in children from as early as the 1940s, with Garceau et al. describing the first anterior tibialis tendon transfer for recurrent clubfoot. ${ }^{3}$ 
A balanced foot is most often the primary goal of tendon transfers. It is used to regain active function or as a tether to keep the foot in a more functional position. ${ }^{4-5}$ Most studies, however, use only clinical and subjective parameters to evaluate the patient before surgery, as well as to assess surgical outcomes. ${ }^{5}$ In an unpublished study, Tennant et al. aimed to objectively define gait abnormalities and changes after tendon surgery using gait analysis. ${ }^{6}$
Quantitative gait analysis investigates foot motion during dynamic weight-bearing. ${ }^{7}$ A motion analysis laboratory allows assessment of gait at multiple joints, allowing differentiation of primary and compensatory abnormalities. ${ }^{4}$ Temporo-spatial, kinetic, and kinematic parameters can be analyzed easily through graphs (Figure 1). Gait analysis provides a more objective and accurate assessment of gait compared to clinical examination..$^{8-9}$
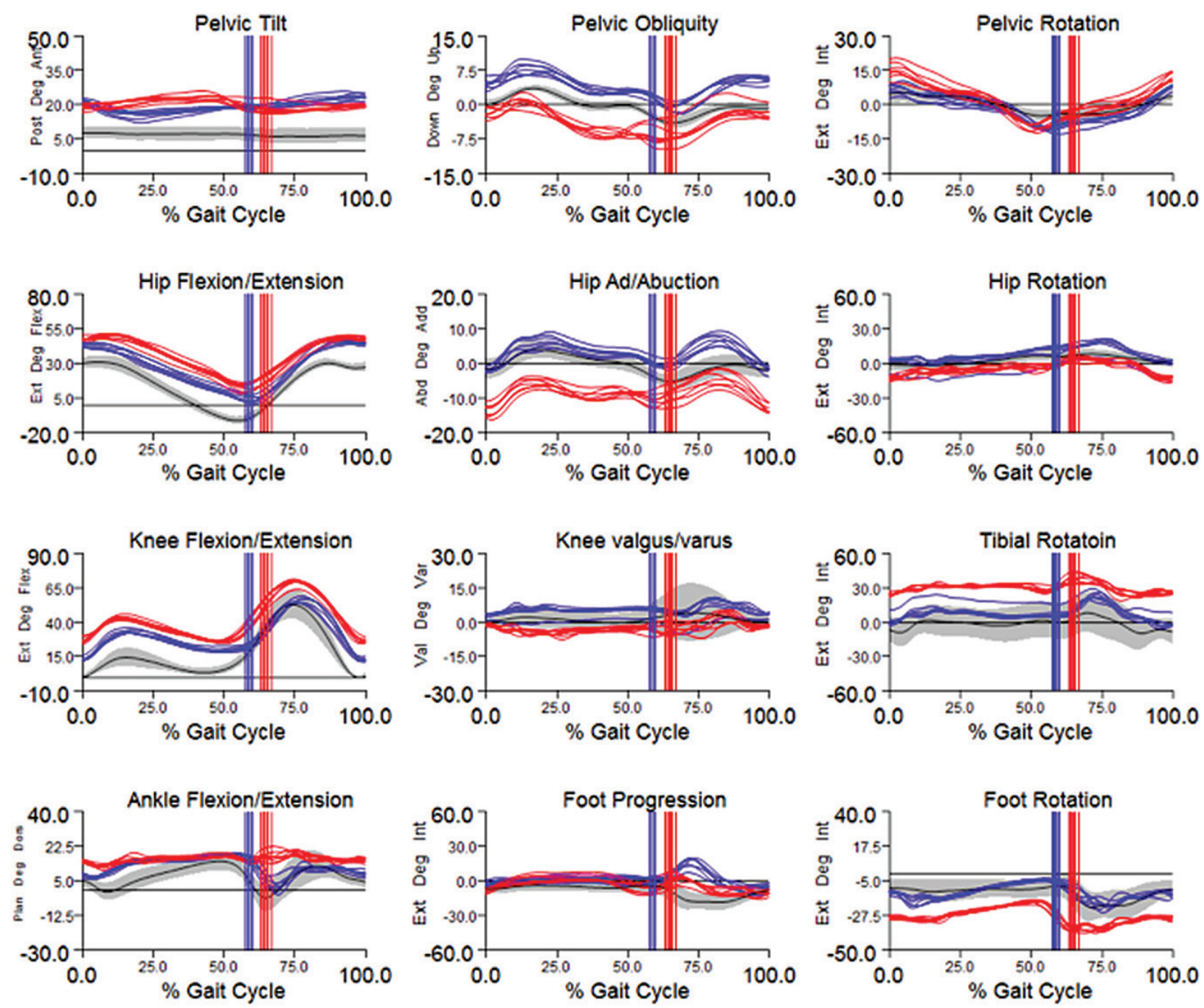

$\begin{array}{ll}\begin{array}{l}\text { Speed } \\ \text { Stride } \\ \text { Cycle Time }\end{array} & \begin{array}{c}0.91 \mathrm{~m} / \mathrm{s} \\ \text { Wid(4) } 0.13 \pm 0.02 \\ \text { Computed: } 1.02\end{array} \\ \text { Step Length } & \text { Measure } \pm \text { StdDev (Count) } \\ \text { Steps / Minute } & \text { Left: } 0.45 \pm 0.04 \mathrm{~m} \mathrm{(3)} \\ \text { Strides / Minute } & \text { Left: } 119.34 \pm 1.14(3) \\ \text { Initial DBL Support } & \text { Left: } 57.47 \pm 0.51 \text { (7) }\end{array}$

0.49 Statures/s
Len(14) $0.93 \pm 0.05 \mathrm{~m}$
Actual (14) $1.03 \pm 0.03 \mathrm{~s}$
Measure \pm StdDev (Count)
Right $0.46 \pm 0.03 \mathrm{~m} \mathrm{(3)}$
Right : $111.35 \pm 1.00(3)$
Right : $59.39 \pm 2.55(7)$
Right $0.12 \pm 0.00 \mathrm{~s}(3)$

Figure 1. Sample output of the Philippine General Hospital Motion Analysis Laboratory showing kinematic and temporal parameters through the entire gait cycle. 
Motion analysis was first applied to children with cerebral palsy in the 1960s at the Shriners Hospital in San Francisco. ${ }^{8}$ Today, the clinical role of quantitative gait analysis is still debatable, with numerous studies published studying its practicability and reliability. ${ }^{8}$ Lofterod et al. showed that preoperative gait analysis led to better diagnosis of patients with cerebral palsy, reducing the number of procedures done by $13 \% .{ }^{9}$

After studying 134 children using a motion analysis program, Wheelwright et al. found a quadratic relationship between age and step length. Age and cadence, on the other hand, have an inverse quadratic relationship. Both step length and cadence vary significantly between the sexes. ${ }^{10}$

The Gait Deviation Index (GDI) simplifies the complex data gathered in a motion analysis laboratory. It was developed by Schwartz and Rozumalski to account for the complexity and interdependence of gait pathologies in different planes of motion. It is presented on a 100 point scale, with a standard deviation of 10 points. A GDI $\geq 100$ indicates the absence of gait pathology. Every 10 points below 100 correspond to one standard deviation away from the mean of the control group.

The GDI is also a sensitive measure to differentiate between Gillette Functional Assessment Walking Scale (FAQ) levels. One of the commonly used parents reported questionnaires in the analysis of gait impairment. Schwartz and Rozumalski found that the GDI was normally distributed at each FAQ level, proving that the GDI is related to functional walking ability. ${ }^{11}$

One of this study aims was to assess the outcomes of corrective surgery in children with foot deformities using both functional outcome measures like the FAQ GDI, and Hoffer's criteria and temporospatial parameters of gait determined by the motion analysis software. The authors also wanted to determine if any improvement in function would also improve the quantitative gait analysis.

\section{METHODS}

\section{Ethical Considerations}

The study was conducted with the approval of the University of the Philippines Manila Research Ethics Board (UPMREB). The UPMREB did not deem it necessary to obtain informed consent, as data were gathered purely through a review of paper and electronic records.

\section{Population}

The Gait Motion Analysis Laboratory of the Philippine General Hospital (PGH) records from the time it was established in 2015 to October 2017 were reviewed. All patients up to 18 years of age who underwent corrective foot and ankle surgeries with pre and postoperative gait evaluation were included. The patients were seen at the Pediatric Orthopedic Outpatient Clinic of the PGH. Treatment plans were discussed and carried out by Orthopedic Residents in training and Orthopedic Consultants.

\section{Gait Analysis}

A trained Gait Analysis Technician runs the entire gait analysis protocol. The technician conducts a short history, which includes whether the patient needs walking aids or orthoses. He also measures the range of motion of the hips, knees, and ankles, and attaches motion sensors on predetermined surface markers. Each patient is then instructed to walk back and forth as he usually would, at least four times, while six cameras are recording. Motion capture software is then able to generate data based on the recordings.

\section{Outcome Measures}

Surgical outcomes were measured using temporospatial parameters (step length and cadence) compared to typical values reported by Wheelwright et al. in 1993. The GDI was computed using an Excel spreadsheet developed based on Schwartz's original description. FAQ scores were extrapolated from the GDI and compared pre and postoperatively. ${ }^{10}$

\section{RESULTS}

\section{Population}

Five subjects met the inclusion criteria. There were four male subjects with a mean age of 10.5 years (6.316.25 years). Two subjects with idiopathic deformities had unilateral involvement, while the other three with neurogenic deformities had bilateral involvement (Table 1). One patient underwent surgery for both feet, and one patient underwent surgery for his hip subluxation during the same setting. Two patients have had prior procedures for their foot deformities, including percutaneous tenotomies and an open Tendon of Achilles lengthening.

\section{Temporo-spatial Parameters}

The patient's cadence and step length were compared to age and sex-matched normal children using Wheelwright's equations. ${ }^{10}$ While our patients did not gain normal cadence and step lengths, their postoperative values still show an improvement (Table 2).

\section{Gait Deviation Index}

In all five patients, the Gait Deviation Index (GDI) was computed for both feet. Four patients showed better GDI postoperatively, with a mean of $6 \%$ improvement on the right and $11 \%$ improvement on the left. The operated limbs had a mean improvement of $12 \%$, while the non-operated side improved by $4 \%$ (Figure 2).

\section{Functional Outcome}

Functional outcome was measured using the FAQ scores and Hoffer's criteria when he first described splitting anterior tibialis tendon transfers in 1974 (Table 3). ${ }^{12} \mathrm{~A}$ child with an FAQ score of 10 can keep up with his peers, while 6 is the lower limit of community ambulation. Only one patient was not a community ambulator before surgery. 
Table 1. Patient Characteristics

\begin{tabular}{|c|c|c|c|c|c|c|c|c|c|}
\hline Patient & $\begin{array}{l}\text { Age at } \\
\text { time of } \\
\text { surgery }\end{array}$ & Sex & $\begin{array}{c}\text { Foot } \\
\text { pathology }\end{array}$ & $\begin{array}{l}\text { Affected } \\
\text { side }\end{array}$ & Other pathology & Foot surgery & Other surgery & $\begin{array}{l}\text { Time from } \\
\text { surgery to } \\
\text { postop gait } \\
\text { analysis }\end{array}$ & $\begin{array}{l}\text { Complications/ } \\
\text { Other notes }\end{array}$ \\
\hline 1 & $16 y 3 \mathrm{mo}$ & $F$ & neurogenic & B & $\begin{array}{l}\text { likely Charcot } \\
\text { Marie Tooth } \\
\text { (no genetic } \\
\text { testing done) }\end{array}$ & $\begin{array}{l}\mathrm{L}-\text { the release of } \\
\text { the plantar fascia, } \\
\text { abductor hallucis, } \\
\text { FDL, FHL, transfer } \\
\text { of tibialis posterior } \\
\text { with the rerouting } \\
\text { of tibialis anterior } \\
\text { and peroneus brevis, } \\
\text { gastrocnemius } \\
\text { recession (Bridle } \\
\text { procedure) }\end{array}$ & & $13 \mathrm{mo}$ & $\begin{array}{l}\text { postop wound } \\
\text { complication } \\
\text { from the } \\
\text { suspensory } \\
\text { button plantar } \\
\text { neuroma }\end{array}$ \\
\hline 2 & $9 y 5 \mathrm{mo}$ & M & idiopathic & $\mathrm{R}$ & $\begin{array}{l}\text { Down syndrome } \\
\text { R hip subluxation }\end{array}$ & $\begin{array}{l}\text { gastrocnemius } \\
\text { recession, Jones EHL } \\
\text { transfer }\end{array}$ & $\begin{array}{l}\text { VDRO of R } \\
\text { proximal femur }\end{array}$ & $11 \mathrm{mo}$ & $\begin{array}{l}\text { failure of } \\
\text { fixation on R hip }\end{array}$ \\
\hline 3 & 13 y $1 \mathrm{mo}$ & $M$ & neurogenic & B & $\begin{array}{l}\text { myelo- } \\
\text { meningocele } \\
\text { coarctation of } \\
\text { the aorta }\end{array}$ & $\begin{array}{l}\text { R - EHL transfer, } \\
\text { Dwyer osteotomy, } \\
\text { plantar fascia release, } \\
\text { SPLATT } \\
\text { L - EHL transfer, } \\
\text { plantar fascia release, } \\
\text { tibialis posterior } \\
\text { lengthening }\end{array}$ & $\begin{array}{l}1 \text { previous surgery for } \\
\text { myelomeningocele }\end{array}$ & $6 \mathrm{mo}$ & \\
\hline 4 & $7 y 7 m o$ & M & idiopathic & $\mathrm{L}$ & & $\begin{array}{l}\text { TA lengthening, } \\
\text { plantar fascia release, } \\
\text { posterior release, } \\
\text { tibialis anterior } \\
\text { transfer }\end{array}$ & $\begin{array}{l}2 \text { previous } \\
\text { percutaneous } \\
\text { tenotomies }\end{array}$ & $9 \mathrm{mo}$ & \\
\hline 5 & $6 y 4 \mathrm{mo}$ & M & neurogenic & B & $\begin{array}{l}\text { lipomyelo- } \\
\text { meningocele }\end{array}$ & $\begin{array}{l}\mathrm{R} \text { - tibialis posterior } \\
\text { transfer }\end{array}$ & $\begin{array}{l}1 \text { previous surgery for } \\
\text { lipomyelomeningocele } \\
1 \text { previous TA } \\
\text { lengthening }\end{array}$ & $1 y$ & $\begin{array}{l}\text { lost to ff-up } \\
\text { after cast } \\
\text { removal, unable } \\
\text { to do PT }\end{array}$ \\
\hline
\end{tabular}

F-female; M - male; B - both; $R$ - right; L - left; FDL - flexor digitorum longus; FHL - flexor hallucis longus; EHL - extensor hallucis longus; SPLATT - split tibialis anterior tendon transfer; TA - tendon of Achilles; VDRO - varus derotation osteotomy; PT - physical therapy

Table 2. Step Length and Cadence

\begin{tabular}{|c|c|c|c|c|c|c|c|c|c|c|}
\hline \multirow[b]{3}{*}{ Patient } & \multirow[b]{3}{*}{ Normal } & \multicolumn{4}{|c|}{ Step Length Difference (in SD) } & \multirow{3}{*}{ Normal } & \multicolumn{4}{|c|}{ Cadence difference (in SD) } \\
\hline & & \multicolumn{2}{|c|}{ Right } & \multicolumn{2}{|c|}{ Left } & & \multicolumn{2}{|c|}{ Right } & \multicolumn{2}{|c|}{ Left } \\
\hline & & $\begin{array}{c}\text { Preop } \\
\text { (from } \\
\text { normal) }\end{array}$ & $\begin{array}{c}\text { Postop } \\
\text { (from } \\
\text { preop) }\end{array}$ & $\begin{array}{c}\text { Preop } \\
\text { (from } \\
\text { normal) }\end{array}$ & $\begin{array}{c}\text { Postop } \\
\text { (from } \\
\text { preop) }\end{array}$ & & $\begin{array}{c}\text { Preop } \\
\text { (from } \\
\text { normal) }\end{array}$ & $\begin{array}{c}\text { Postop } \\
\text { (from } \\
\text { preop) }\end{array}$ & $\begin{array}{c}\text { Preop } \\
\text { (from } \\
\text { normal) }\end{array}$ & $\begin{array}{c}\text { Postop } \\
\text { (from } \\
\text { preop) }\end{array}$ \\
\hline 1 & 0.725218750 & 6 & 2 & 3 & 0 & 123.3734375 & 3 & 1 & 3 & 0 \\
\hline 2 & 0.622234144 & 6 & 1 & 7 & 0 & 122.7973761 & -3 & -5 & -10 & -9 \\
\hline 3 & 0.712973639 & 5 & 1 & 7 & 3 & 117.0690189 & 0 & 0 & 0 & 0 \\
\hline 4 & 0.563741201 & 3 & 0 & 4 & 2 & 127.8306388 & 0 & 1 & 0 & 0 \\
\hline 5 & 0.518858058 & 5 & 3 & 4 & 2 & 132.0903104 & 0 & 0 & 2 & 1 \\
\hline
\end{tabular}

All five patients either maintained or improved to FAQ 10 after the corrective surgeries. However, only one of them has a Very Good outcome when Hoffer's criteria are used (Table 4).

\section{DISCUSSION}

The complexity of gait, whether expected or pathological, makes it quite challenging to interpret. A multitude of outcome measures has been used by clinicians - from subjective self- or parent-reported questionnaires to statistical analysis using different indices. This study highlights what has been reported by Thomason et al. - that no single outcome measure can be used alone to evaluate a child's gait accurately. ${ }^{1}$ For example, even though our fourth subject was the only one who did not improve GDI, he is also the only subject evaluated as Very Good using Hoffer's criteria. However, like the other four, his FAQ is 10. 


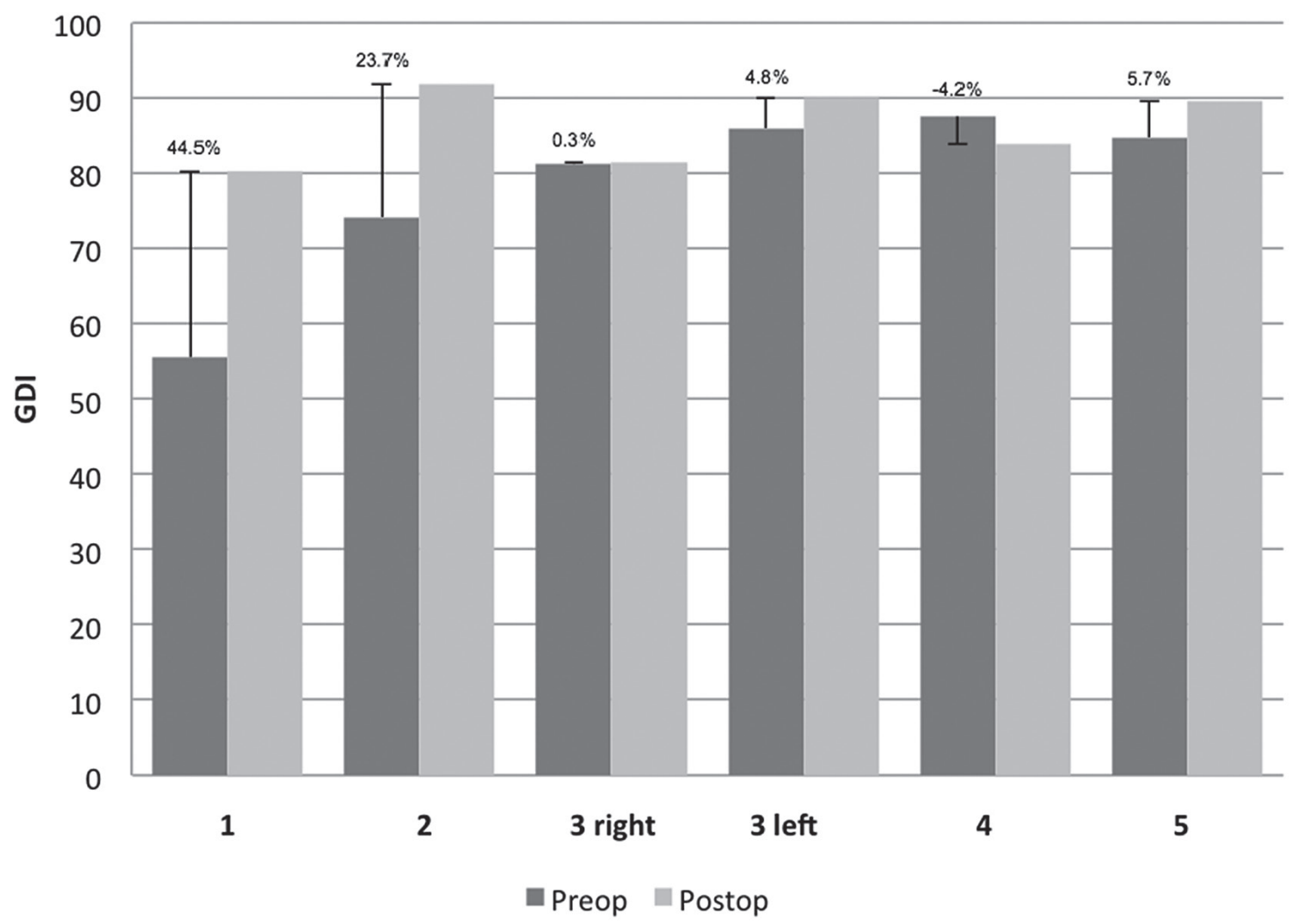

Figure 2. Graph showing the pre and postoperative GDI of the subjects' affected feet, percentage change as labeled. Patient 3 had bilateral surgeries.

Table 3. Hoffer's Criteria

\begin{tabular}{ll}
\hline Very Good & $\begin{array}{l}\text { No deformity postoperatively } \\
\text { Total foot contact on the ground } \\
\end{array}$ \\
& Proper shoe-wearing \\
\hline Satisfactory & Mild vars, valgus, or equinus deformity \\
& Small foot contact \\
& Use of overnight braces \\
\hline Poor & Overcorrection or undercorrection \\
& Equinus $>5^{\circ}$ \\
& Use of braces \\
\hline
\end{tabular}

Table 4. Functional Outcomes

\begin{tabular}{cccccccc}
\multirow{2}{*}{ Patient } & Hoffer's & \multicolumn{2}{c}{ Preop FAQ } & & \multicolumn{2}{c}{ Postop FAQ } \\
\cline { 3 - 4 } \cline { 6 - 7 } & Right & Left & & Right & Left \\
\hline 1 & Poor & 10 & $\underline{6}$ & & 10 & $\underline{10}$ \\
3 & Satisfactory & $\underline{8}$ & 9 & & $\underline{10}$ & 10 \\
3 & Satisfactory & $\underline{10}$ & $\underline{10}$ & & $\underline{10}$ & $\underline{10}$ \\
4 & Very Good & 10 & $\underline{10}$ & & 10 & $\underline{10}$ \\
5 & Poor & $\underline{10}$ & 10 & & $\underline{10}$ & 10 \\
\hline
\end{tabular}

underlined - operated side

The most significant GDI improvement was seen in our patient who had bilateral deformities and underwent a Bridle procedure for the left foot only. Because this patient had no other deformities and no surgery in any other part of her limbs was performed, we can assume that the improved GDI is due to the corrective surgery we performed on her foot. A similar improvement of 2 standard deviations was seen in our patient who underwent a concomitant derotation osteotomy of the ipsilateral proximal femur. In his case, his subluxated hip's surgical correction was probably the main reason for the significant improvement in GDI and not the correction of the foot deformity itself. This illustrates that the GDI can be a sensitive measure of gait pathology when taken as a whole; however, because it is a single number, it cannot tell a clinician which joint pathology or surgery contributes more to the improvement or deviation from normal gait. This is a limitation of GDI, also noted by Cimolin et al. when they evaluated its use in assessing outcomes of gastrocnemius recession for cerebral palsy patients. ${ }^{13}$

While the improvement in GDI of the operated limbs is expected, we also saw a change in the GDI of the nonoperated side. This shows the interplay of the ipsilateral joint pathologies and how even unilateral correction of a deformity can affect the overall gait pattern.

Our results also show that residual deformities and the need for orthotics or assistive aids in ambulation do not preclude an excellent functional outcome. Subjects 1 and 2 had residual deformities but were shown to have the most significant GDI improvement and gained ambulation equivalent to their peers. 
Corrective surgeries for foot deformities should be done to improve gait - in which case, the GDI is an excellent outcome measure. It is made even more useful because it has been shown to correlate with the FAQ making it very easy to understand in practical terms, even by patients and their parents. In cases in which preoperative GDI and FAQ show that a patient is highly functional even with foot deformities, surgical decision-making can then be based only on the goals of proper shoe-wear and cosmesis. Hence, parents can be advised accordingly. Three of our patients already had an FAQ of 10 preoperatively. The surgeries' goals were to maintain their high level of function with correction of their deformities to promote proper shoe-wear. Of the three, one had a Poor surgical outcome with Hoffer's criteria because he still needs an AFO during ambulation. However, this may be because he could not follow-up regularly and did not undergo any physical therapy sessions.

This study's limitation is that there are only five subjects that were included. However, our results show that we can still achieve good outcomes despite our institution's seemingly limited corrective surgery experience for foot deformities in children. We recommend that formal gait analysis be done in all patients undergoing surgery for lower limb deformities, if it is available, not only to serve as a means to monitor a patient's response to surgery and rehabilitation but also to provide data that might be useful in surgical decision making for future patients.

\section{Statement of Authorship}

All authors participated in the data collection and analysis and approved the final version submitted.

\section{Authors Disclosure}

All authors declared no conflicts of interest.

\section{Funding Source}

This paper was funded by Dr. Joana Francesca B. Visperas.

\section{REFERENCES}

1. Gage J. (2009). The identification and treatment of gait problems in cerebral palsy. London: Mac Keith Press Distributed by WileyBlackwell.

2. Sees JP, Miller F. (2013). Overview of foot deformity management in children with cerebral palsy. J Child Orthop. 2013 Nov; 7(5): 373-7. http://doi.org/10.1007/s11832-013-0509-4

3. Garceau GJ. (1972). Anterior Tibial Tendon Transfer for Recurrent Clubfoot [Abstract]. Clinical Orthopaedics and Related Research, 84, 61-65. doi:10.1097/00003086-197205000-00012

4. Harris GF, Marks RM, Smith PA. (2008). Foot ankle motion analysis: clinical treatment and technology. Retrieved September 16, 2017.

5. Wren TAL, Gorton III GE, Õunpuud S, Tucker CA. Efficacy of clinical gait analysis: A systematic review. Gait Posture (2011), doi:10.1016/ j.gaitpost.2011.03.027

6. Tennant S, Douglas C, Thornton M. (2017). GAIT ANALYSIS PRE AND POST TIBIALIS ANTERIOR TENDON TRANSFER FOR PONSETI-TREATED CLUBFOOT DEFORMITY. Bone Joint J, 99-B(SUPP 11), 3. [Internet]. [cited 2017 September 17]. Available from http://bjjprocs.boneandjoint.org.uk/content/99-B/ SUPP_11/3.

7. Vries GD, Roy K, Chester V. (2009). Using Three-Dimensional Gait Data for Foot/Ankle Orthopaedic Surgery. The Open Orthopaedics Journal, 3(1), 89-95. doi:10.2174/1874325000903010089

8. Davids JR. (2006). Quantitative Gait Analysis in the Treatment of Children With Cerebral Palsy. Journal of Pediatric Orthopedics, 26(4), 557-9. doi:10.1097/01.bpo.0000226284.46943.a3

9. Lofterød B, Terjesen T, Skaaret I, Huse AB, Jahnsen R. (2007) Preoperative gait analysis has a substantial effect on orthopedic decision making in children with cerebral palsy: Comparison between clinical evaluation and gait analysis in 60 patients, Acta Orthopaedica, 78:1, 74-80, DOI: 10.1080/17453670610013448

10. Wheelwright EF, Minns RA, Law HT, Elton RA. (2008). Temporal And Spatial Parameters Of Gait In Children. I: Normal Control Data. Developmental Medicine \& Child Neurology, 35(2), 102-13. doi:10.1111/j.1469-8749.1993.tb11612.x

11. Schwartz MH, Rozumalski A. (2008). The Gait Deviation Index: a new comprehensive index of gait pathology. Gait Posture, 28(3), 351-7. doi:10.1016/j.gaitpost.2008.05.001

12. Alter AH. (1974). The split anterior tibial tendon transfer in the treatment of spastic varus hindfoot of childhood [Abstract]. Journal of Pediatric Surgery,9(5), 798. doi:10.1016/0022-3468(74)90167-5

13. Cimolin V, Galli M, Vimercati SL, Albertini G. (2011). Use of the Gait Deviation Index for the assessment of gastrocnemius fascia lengthening in children with Cerebral Palsy. Research in Developmental Disabilities,32(1), 377-381. doi:10.1016/j.ridd.2010.10.017 